\title{
Dual inhibition of EGFR and mTOR pathways in small cell
}

\section{lung cancer}

\author{
K Schmid', Z Bago-Horvath', W Berger², A Haitel', D Cejka ${ }^{3}$, J Werzowa ${ }^{3}$, M Filipits², B Herberger², \\ $H$ Hayden $^{3}$ and W Sieghart ${ }^{*, 3}$
}

'Clinical Institute of Pathology, Medical University of Vienna, Vienna, Austria; ${ }^{2}$ Institute of Cancer Research, Department of Medicine I, Medical University of Vienna, Vienna, Austria; ${ }^{3}$ Department of Internal Medicine III, Medical University of Vienna, Waehringer Guertel I 8-20, A-1090, Vienna, Austria

BACKGROUND: In this report we investigated the combination of epidermal growth factor receptor (EGFR) and mammalian target of rapamycin (mTOR) pathway inhibition as a possible new therapeutic strategy for small cell lung cancer (SCLC).

METHODS: EGFR, p-AKT, p-ERK, p-mTOR and p-p70s6K protein expressions were studied by immunohistochemistry in 107 small cell lung carcinomas and correlated with clinicopathological parameters. Cells of SCLC were treated with erlotinib \pm RAD00I and analysed for cell viability, proliferation, autophagy, and pathway regulation.

RESULTS: Epidermal growth factor receptor, p-AKT, p-ERK, p-mTOR, and p-p70s6K were expressed in 37, 24, 13, 55 and $91 \%$ of the tumour specimens of all SCLC patients, respectively, and were not associated with disease-free or overall survival. The expression of EGFR was lower in neoadjuvant-treated patients $(P=0.038)$; mTOR pathway activation was higher in the early stages of disease $(P=0.048)$. Coexpression of EGFR/p-mTOR/p-p70s6K was observed in $28 \%$ of all patients. EGFR immunoreactivity was associated with $\mathrm{p}$-ERK and $\mathrm{p}$-mTOR expression $(P=0.02$ and $P=0.000 \mathrm{I})$; $\mathrm{p}$-mTOR immunoreactivity was associated with $\mathrm{p}$-p70s6K expression $(P=0.00 \mathrm{I})$. Tumour cells comprised a functional EGFR, no activating mutations in exons $|8-2|$, and resistance to RAD00I monotherapy. We found synergistic effects of erlotinib and RAD00I combination therapy on the molecular level, cell viability, proliferation and autophagy.

CONCLUSIONS: The combined inhibition of EGFR/mTOR pathways could be a promising approach to treat SCLC.

British Journal of Cancer (20I0) 103, 622-628. doi: I0. I038/sj.bjc.660576I www.bjcancer.com

Published online 3 August 2010

(c) 2010 Cancer Research UK

Keywords: small cell lung cancer; EGFR; mTOR; erlotinib; RAD00 I; targeted therapy

The options for successful treatment of small cell lung cancer (SCLC) are still very poor. From the time of diagnosis, the median survival rates for SCLCs are 15-20 (limited disease SCLC) and $8-13$ months (extended disease SCLC), respectively (Puglisi et al, 2010); therefore, new therapeutic strategies are urgently needed.

The epidermal growth factor receptor (EGFR) pathway is a wellknown molecular target in several human tumours. Small molecules inhibiting EGFR such as erlotinib or gefitinib as well as anti-EGFR antibodies such as cetuximab were successfully tested in non-SCLC, head and neck, pancreatic and colon cancer (Ciardiello and Tortora, 2008).

Until now, the EGFR pathway has not been studied extensively in SCLC. There are little and controversial data about the presence of EGFR in SCLC tissue (Fischer et al, 2007). It was shown that treatment of SCLC cell lines with a monoclonal EGFR antibody reduced invasiveness of tumour cells in vitro (Damstrup et al, 1998). The tyrosin kinase inhibitor gefitinib, directed against the tyrosin kinase domain of the EGFR, showed single-agent activity against SCLC cells (Tanno et al, 2004), and reverted resistance to the chemotherapeutic topotecan in vitro (Nakamura et al, 2005),

*Correspondence: Dr W Sieghart;

E-mail: wolfgang.sieghart@meduniwien.ac.at

Revised 13 May 20 I0; accepted 7 June 20 I0; published online 3 August 2010 but failed to show clinical benefit in a recent phase II clinical trial in patients with SCLC (Moore et al, 2006). These data suggest that targeting a single pathway in SCLC may not be efficient enough for successful treatment of this deadly disease.

The mammalian target of rapamycin (mTOR) was intensively studied in a multitude of human tumour entities over the past couple of years. Different mitogens activate AKT, which controls mTOR activation by phosphorylation of TSC2, a component of tuberous sclerosis complexes 1 and 2. Activated mTOR phosphorylates $4 \mathrm{EBP}-1$ and $\mathrm{p}$-p70s6K, which leads to protein translation and tumour growth (Bjornsti and Houghton, 2004). AKT can also be activated by the EGFR (Ono and Kuwano, 2006), which represents a possible molecular link between the mTOR and the EGFR pathways.

The mTOR inhibitors CCI-779 and everolimus (RAD001) have already been approved for treatment of advanced renal cancer (Hudes et al, 2007; Motzer et al, 2008); together with other mTOR inhibitors, they are under clinical investigation for several other cancer indications. Although there is evidence that the mTOR pathway is active in SCLC cell lines (Fischer et al, 2007), mTOR pathway expression in SCLC tissue has not been investigated until now. The mTOR pathway may be involved in mechanisms of SCLC cells to escape cell death after treatment with DNA-damaging agents, as the mTOR inhibitor CCI-779 restored sensitivity of SCLC cells to cisplatin treatment (Belyanskaya et al, 2005; Wu et al, 
2005). However, similar to gefitinib therapy, CCI-779 and RAD001 monotherapy achieved only little benefit for SCLC in recent phase II clinical trials (Pandya et al, 2005; Owonikoko et al, 2008).

Given the molecular connection of the EGFR and mTOR pathways, we hypothesised that dual inhibition of both pathways may be a suitable new strategy to treat SCLC. Thus, we investigated single and coexpression of both pathways in 107 SCLC tissue samples, their correlation with clinical-pathological parameters, and analysed efficacy of anti-EGFR therapy plus mTOR inhibition in SCLC cell lines.

\section{MATERIALS AND METHODS}

\section{Patients and tissue samples}

The study comprised 107 patients (69 males and 38 females), median age 62 years (range 35-92 years), who underwent surgery for SCLC at the Department of Cardio-Thoracic Surgery, Medical University of Vienna, Austria. After surgery, tissue samples were fixed in $7.5 \%$ buffered formalin and embedded in paraffin for routine diagnostics. Neuroendocrine tumour differentiation was confirmed by immunohistochemical staining for neuroendocrine markers (chromogranin A and/or synaptophysin). Tumours were staged according to the International Union Against Cancer (UICC) 2004 issue of the TNM system and revealed pT1 in $36(34 \%)$, pT2 in $55(51 \%)$, pT3 in $4(4 \%)$ and pT4 in $12(11 \%)$ cases; lymph node metastases were present in $57(53 \%)$ cases $(\mathrm{pN} 1, \mathrm{pN} 2$ and $\mathrm{pN} 3$ in 30 , 21 and $2 \%$, respectively). TNM stages corresponded to UICC stages IA, IB, IIA, IIB, IIIA and IIIB in $22(21 \%), 23(21 \%), 9(8 \%), 18$ $(17 \%), 22(21 \%)$ and $13(12 \%)$ cases, respectively. The clinical follow-ups of the patients were retrospectively collected from the archives of the Department of Cardio-Thoracic Surgery, Medical University of Vienna, and respective hospitals performing their follow-ups; median-disease free and overall survival were 11.5 and 20.5 months, respectively (both range $0-179.9$ months). In all, 20 (19\%) patients received preoperative chemotherapy (cisplatin and etoposid). Adjuvant chemotherapy was known for 50 (47\%) patients (cisplatin and etoposid, cisplatin and adriamycin or cyclophosphamid and oncovin; in some cases topotecan was given in second line). In all, $56(52 \%)$ patient suffered tumour recurrence and 48 $(45 \%)$ died of tumour progression during the observation period.

\section{Immunohistochemistry}

Immunohistochemistry was performed on $4 \mu \mathrm{m}$ paraffin sections from one representative tissue block per patient stored at the archives of the Department of Pathology, Medical University of Vienna, using antibodies against EGFR (DAKO, Glostrup, Denmark) phospho-mTOR, phospho-p70s6K, phospho-AKT and phospho-ERK (all from Cell Signaling Technology, Danvers, MA, USA).

Epidermal growth factor receptor kit immunostaining was performed according to the manufacturer's instructions. Pretreatment was protease (Sigma, Steinheim, Germany) for p-AKT immunostaining, microwave $(5 \times 5 \mathrm{~min}, 900 \mathrm{~W})$ for p-ERK immunostaining, and autoclave (20 min, 1 bar) for p-mTOR and p-p70s6K immunostaining. After blocking, samples were incubated with primary antibodies for $1 \mathrm{~h}$ at room temperature. Dilutions for anti-p-AKT, anti-p-ERK, anti-p-mTOR and antip-p70s6K were $1: 25,1: 100,1: 100$ and $1: 400$, respectively. After applying a biotinylated secondary antibody and tertiary reagent (Vector-Laboratories, Bulingam, CA, USA) the antibody binding was visualised by diaminobenzidine (Serva, Heidelberg, Germany) and $\mathrm{H}_{2} \mathrm{O}_{2}$. Colon carcinoma tissue served as positive control. Negative controls were treated with isotype IgG control antibodies. Immunoreactive tumour cells were counted in 10 high-power fields $(\times 400)$ by $\mathrm{KS}$ and $\mathrm{ZB}$ independently. The scoring system integrated intensity and extent of immunostaining: the number of positive tumour cells was scored $0(<10 \%), 1$ (10-24\%), 2 $(25-49 \%), 3(50-79 \%)$ and $4(80-100 \%)$. Intensity of staining was scored 0 (negative), 1 (weak) or 2 (strong). The results of the extent and intensity of staining of tumour cells were summarised to assess the final score.

\section{Chemicals}

RAD001 (everolimus) was provided by The Novartis Institutes for BioMedical Research Basel, Oncology, Switzerland. Erlotinib was dissolved in DMSO and provided by Professor Thomas Grunt (Department of Medicine I, Institute of Cancer Research, Medical University of Vienna, Austria). Controls were treated with appropriate concentrations of DMSO.

\section{Cell culture}

Two SCLC cell lines were used: GLC-4, donated by Dr EG deVries, Groningen, The Netherlands (Zijlstra et al, 1987), and VL-68 (Berger et al, 2001). Cells were grown in RPMI-1640 medium supplemented with $10 \%$ heat-inactivated fetal calf serum and with $1 \%$ penicillin - streptomycin in a humidified atmosphere containing $5 \% \mathrm{CO}_{2}$ (all from Gibco Life Technologies, Paisley, UK). Cell counts were determined using a CC-108 microcellcounter (Sysmex, Kobe, Japan). Cells growing in logarithmic phases of growth were used for all the studies described below.

\section{MTT assay}

Cells $\left(2 \times 10^{5}\right.$ cells per well) in the logarithmic phase of growth were plated in $0.5 \mathrm{ml}$ complete medium in 48 -well plates and allowed to attach overnight. The next day, RAD001, erlotinib or a combination of both were added at concentrations as indicated. The final concentration of DMSO never exceeded $0.5 \%$. Cells were incubated for $72 \mathrm{~h}$ at $37^{\circ} \mathrm{C}$ in a humidified atmosphere containing $5 \% \mathrm{CO}_{2}$. Afterwards, medium was replaced by $100 \mu \mathrm{l}$ Opti-MEM medium containing $1 \mathrm{mg} \mathrm{ml}^{-1}$ Thiazolyl Blue Tetrazolium Bromide (MTT; Sigma-Aldrich, Vienna, Austria) and incubated for $1 \mathrm{~h}$ at $37^{\circ} \mathrm{C}$. The cells were then lysed by adding $100 \mu \mathrm{l}$ DMSO. Absorbance was recorded by a BioTek Synergy HT plate reader (BioTek Instruments, Winooski, VT, USA) at $570 \mathrm{~nm}$. All experiments were run in triplicates.

\section{Cell cycle analysis, cell proliferation and apoptosis}

Small cell lung cancer cells $\left(0.4 \times 10^{6}\right.$ per $\left.\mathrm{ml}\right)$ were seeded in $25 \mathrm{~cm}^{2}$ tissue culture flasks and then incubated with RAD001, erlotinib or with a combination of both at concentrations as indicated. After $48 \mathrm{~h}$, cells were harvested and propidium iodide staining was performed as reported by Sieghart et al (2007). Cell cycle analysis (including sub-G1 peak for apoptosis) was performed using a FACSCalibur flow cytometer (Becton Dickinson, Heidelberg, Germany) and cell cycle distribution was calculated using ModFit LT software (Verity Software House, Topsham, ME, USA). To further analyse apoptosis, we performed DAPI staining according to the study group of Dornetshuber et al (2007). Cell proliferation was measured using the $3 \mathrm{H}$-thymidine incorporation assay (Dornetshuber et al, 2007) $24 \mathrm{~h}$ after treatment of SCLC cells with erlotinib, RAD001 or a combination of both at indicated concentrations.

\section{Quantification of autophagy by an analysis of acidic vesicular organelle-positive cells}

The effect of the investigated compounds alone and in combination on autophagy was assessed in both SCLC models by quantification of acidic vesicular organelles. In brief, cells were 
seeded at $3 \times 10^{5}$ per well in six-well plates and treated with erlotinib, RAD001 and their combination at concentrations as indicated. After $48 \mathrm{~h}$, cells were trypsinised, washed in PBS and stained with acridine orange $\left(1 \mu \mathrm{g} \mathrm{ml}^{-1}\right.$ in serum- and phenol redfree medium; Sigma-Aldrich) for $15 \mathrm{~min}$ at $37^{\circ} \mathrm{C}$. The cells were analysed through flow cytometry for green $(510-530 \mathrm{~nm})$ and red $(>650 \mathrm{~nm})$ fluorescence emission from $2 \times 10^{4}$ cells illuminated with blue $(488 \mathrm{~nm})$ excitation light, and were measured with FACSCalibur (Becton Dickinson) using CellQuest software. Cells positive for red fluorescence were scored positive for acidic vesicular organelles.

\section{EGFR sequencing in SCLC cells}

Genomic DNA used as template for sequencing EGFR exons 18-21 was extracted from the GLC- 4 and VL- 68 cell lines as described previously (Lynch et al, 2004). In brief, polymerase chain reaction (PCR) fragments were sequenced and analysed in both sense and anti-sense directions for the presence of heterozygous mutations. The primer sequences for exon 18 were $5^{\prime}$-CTGAGGTGA CCCTTGTCTCTG-3' (forward) and 5'-CCAAACACTCAGTGAAA CAAAGAG-3' (reverse); for exon 19 5'-TGCCAGTTAACGTC TTCCTT- $3^{\prime}$ (forward) and $5^{\prime}$-CAGGGTCTAGAGCAGAGCAG- $3^{\prime}$ (reverse); for exon 20 5'-CATTCATGCGTCTTCACCTG-3' (forward) and $5^{\prime}$-TTATCTCCCCTCCCCGTATC-3' (reverse); and for exon $215^{\prime}$-CTTCCCATGATGATCTGTCC-3' (forward) and $5^{\prime}$-TTA TCTCCCCTCCCCGTATC- $3^{\prime}$ (reverse). Mutations were identified by visual analysis of the sequence chromatograms using SeqScape (Applied Biosystems, Foster City, CA, USA).

\section{Western blot}

Cells $\left(2 \times 10^{6}\right.$ cells per well $)$ in the logarithmic phase of growth were plated in $2 \mathrm{ml}$ complete medium in six-well plates and allowed to attach overnight. Cells were treated with RAD001, erlotinib or with a combination of both at concentrations as indicated. They were then incubated for $72 \mathrm{~h}$ at $37^{\circ} \mathrm{C}$ in a humidified atmosphere containing $5 \% \mathrm{CO}_{2}$. After harvesting of the probes they were blotted according to standard procedures and incubated with monoclonal antibodies binding to EGFR (Santa Cruz Biotechnology, Santa Cruz, CA, USA, 1:1000), p-AKT (1:5000), p-mTOR (1:3000), p-p70s6K (1:3000), p-ERK (all from Cell Signaling, $1: 5000$ ) or Actin (Sigma-Aldrich; 1:40000), respectively. Reactive bands were detected by chemiluminescence (CSPD substrate; Tropix Inc., Bedford, MA, USA). Equal protein loading in each lane was documented by detecting Actin protein expression.

\section{Statistical analysis}

Association of different protein immunoreactivity among each other and with clinicopathological parameters was investigated using the $\chi^{2}$ test. Disease-free and overall survival was assessed using the Kaplan-Meier method. Cell culture data are presented as mean \pm s.d. Differences among treatment groups were calculated using one-way ANOVA, and Bonferroni's test was used for post hoc comparisons. For all tests, a two-tailed $P$-value of $\leqslant 0.05$ was considered significant.

\section{RESULTS}

\section{EGFR pathway is expressed in SCLC}

Overall, EGFR, p-AKT and p-ERK expression was detected in 37, 24 and $13 \%$ of tumour specimens (Figure 1 and Table 1). P-AKT and p-ERK showed cytoplasmatic staining pattern, whereas EGFR was expressed cytoplasmatic and membranous. The expression of EGFR and p-ERK as well as of p-AKT and p-ERK was positively associated $(P=0.02$ and $P=0.0001)$, whereas EGFR and $\mathrm{p}$-AKT expression was not $(P>0.05$, Table 2). Patients receiving preoperative chemotherapy were less likely to present with EGFR-positive tumours than patients without preoperative chemotherapy (14 vs 40\%, $P=0.038$ ), but no influence of preoperative chemotherapy on $\mathrm{p}$-AKT or $\mathrm{p}$-ERK tumour expression was found (both $P>0.05$, Table 2). The expression of EGFR, p-AKT and p-ERK was not associated with tumour stage, disease-free or overall survival on univariate analysis (all $P>0.05$, Table 2 ).

\section{mTOR pathway is active in SCLC}

Phospho-mTOR and p-p70s6K immunoreactivities were detected in 55 and $91 \%$ tumour specimens of all SCLC patients (Figure 1 and Table 1). Phospho-mTOR was expressed in the cytoplasma and p-p70s6K was detected in the cytoplasma and/or in the nucleus. Mitoses showed a remarkable cytoplasmatic p-p70s6K staining pattern (see arrows in Figure 1B). There was a significant association of $\mathrm{p}$-mTOR and p-p70s6K $(P=0.001$, Table 2$)$. Higher tumour stages were associated with lower p-mTOR expression $(P=0.048)$, but no association between $\mathrm{p}$-mTOR expression and nodal stage was found $(P>0.05$, Table 2$)$. Higher tumour and nodal stages presented with lower p-p70s6K tumour expression $(P=0.02$ and $P=0.001$, Table 2$)$. Preoperative chemotherapy had no influence on p-mTOR and p-p70s6K tumour expression. Phospho-mTOR and p-p70s6K tumour expression had no influence on disease-free and overall survival in univariate analysis $(P>0.05$, Table 2).

\section{EGFR and mTOR pathways are coexpressed in SCLC}

In all, $28 \%$ of all patients showed coexpression of both pathways in terms of EGFR, p-mTOR and p-p70s6K positivity in SCLC tumour specimens. There was no significant difference in tumour or nodal stage distribution and administration of preoperative chemotherapy compared with patients without pathway coexpression (all $P>0.05)$. A positive association between EGFR and p-mTOR expression $(P=0.0001)$, but not between EGFR and p-p70s6K expression $(P>0.05$, Table 2$)$, was found. There was no association between p-ERK, p-mTOR and p-p70s6K as well as p-AKT, p-mTOR and p-p70s6K tumour expression (all $P>0.05$, Table 2).

\section{Synergistic effects of erlotinib and RAD001 combination therapy on SCLC cells}

Given a potential target population of $28 \%$ patients coexpressing EGFR and mTOR pathways, we then evaluated the efficacy of RAD001 and erlotinib in SCLC cell lines (Figure 2A and B). Small cell lung cancer cells were treated with increasing doses of $\operatorname{RAD} 001(5,10,20$ and $50 \mathrm{nM})$ and erlotinib (5 and $10 \mu \mathrm{M})$ for $72 \mathrm{~h}$.

RAD001 at doses of 5-50 nM had no significant anti-tumour effect. However, $5 \mu \mathrm{M}$ of erlotinib achieved a mild reduction of viable GLC-4 (16\%) and VL-68 cells (26\%) (see Figure 2A and B, $P<0.001$ compared with control) and this effect could not be increased using $10 \mu \mathrm{M}$ of erlotinib. We did not use higher doses of erlotinib, as $5 \mu \mathrm{m}$ erlotinib correspond to plasma concentrations in humans that can be achieved after oral dosing with $150 \mathrm{mg}$ erlotinib per day (Hidalgo et al, 2001).

Combination treatment of VL-68 and GLC-4 cells (Figure 2A and $\mathrm{B}$ ) revealed a strong, significant reduction of cell viability by up to $86 \%$ (s.d. $\pm 0.74 \%$ ) and $72 \%$ (s.d. $\pm 2 \%$ ), respectively, compared with the untreated control and the respective erlotinib or RAD001 monotherapy (all $P<0.0001$ ).

For further mechanistic insights, we analysed respective drug effects on cell DNA synthesis $\left({ }^{3} \mathrm{H}\right.$-thymidine incorporation assay), cell cycle phases (PI staining), autophagy (acidic vesicular organelles) and apoptosis (DAPI staining and sub-G1 peak in cell 


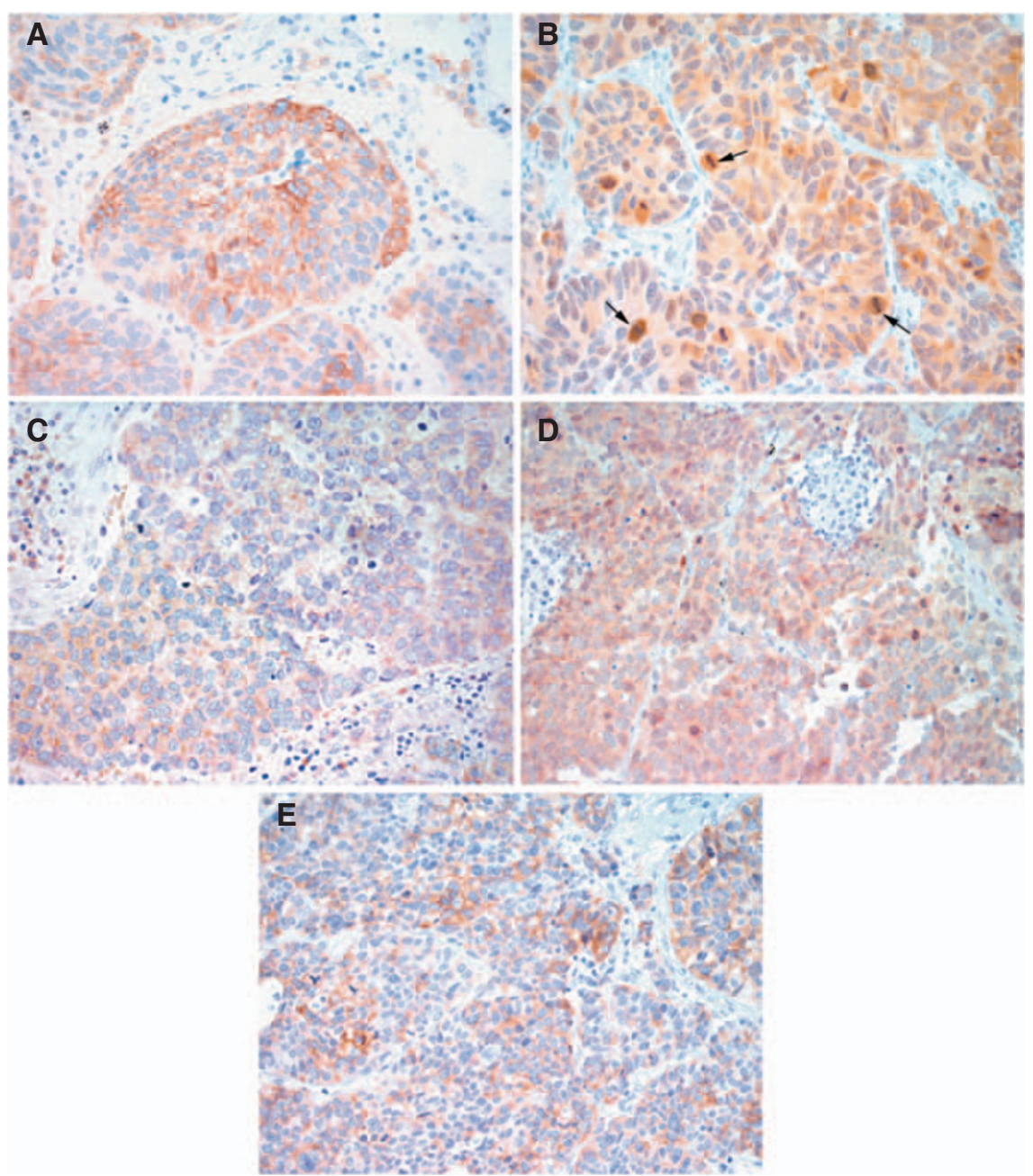

Figure I Immunostaining of EGFR and mTOR pathways in SCLC. Immunohistochemical staining of SCLC for (A) p-mTOR, (B) p-p70s6K (strongly stained mitoses are marked by arrows), $(\mathbf{C})$ p-AKT, $(\mathbf{D})$ p-ERK and $(\mathbf{E})$ EGFR (all magnification $\times 400$ ).

Table I EGFR and mTOR pathway immunostaining in I07 SCLC tissue specimens

\begin{tabular}{lccc}
\hline Immunohistochemical staining & Negative & Weak & Strong \\
\hline EGFR & $67(63 \%)$ & $24(22 \%)$ & $16(15 \%)$ \\
P-ERK & $93(87 \%)$ & $8(7 \%)$ & $6(6 \%)$ \\
P-AKT & $81(76 \%)$ & $20(19 \%)$ & $6(5 \%)$ \\
P-mTOR & $48(45 \%)$ & $41(38 \%)$ & $18(17 \%)$ \\
P-P70s6K & $10(9 \%)$ & $40(38 \%)$ & $57(53 \%)$ \\
\hline
\end{tabular}

Abbreviations: $E G F R=$ epidermal growth factor receptor; $m T O R=$ mammalian target of rapamycin; $\mathrm{p}$-AKT = phosphorylated AKT; $\mathrm{p}$-ERK= phosphorylated extracellular signal-regulated kinase; $\mathrm{SCLC}=$ small cell lung cancer.

cycle analysis). Treatment of VL-68 cells with $5 \mu \mathrm{M}$ erlotinib for $24 \mathrm{~h}$ revealed a strong reduction of DNA synthesis by $74 \%$ compared with control (Figure 2C). Addition of RAD001 at all doses further decreased DNA synthesis of erlotinib to $14 \%$ of untreated control $(P<0.003$, compared with erlotinib or RAD001 monotherapy, respectively), thus showing a cooperative inhibitory effect of this drug combination on SCLC cell proliferation. Similar results were observed for the GLC-4 cell line (data not shown) and confirmed by cell cycle analysis. Cell cycle analysis showed a significant G0/G1 arrest with a corresponding significant reduction of S phase of tumour cells upon combination treatment compared with respective controls (see Figure 2D). Although apoptosis was no major contributor to the observed anti-tumour effects (unremarkable DAPI staining, no evidence for a sub-G1 peak in FACS analysis, data not shown), there was a significant effect of combinatorial therapy on autophagy. Treatment of VL-68 and GLC-4 cell lines with erlotinib and RAD001 led to a 22- and 47-fold induction of autophagy compared with control whereas respective monotherapies revealed only a little effect (Figure 2E).

\section{Regulation of EGFR and mTOR pathways by erlotinib and RAD001 monotherapy and upon combination}

Given the strong synergistic antitumour effect of erlotinib and RAD001 combination therapy compared with the respective monotherapy, we evaluated the mechanism of action of this combination by monitoring therapy-associated changes in both pathways (Figure $3 \mathrm{~A}-\mathrm{C}$ ); both cell lines showed a weak EGFR expression on the protein level (Figure 3A). No mutations were found in EGFR gene exon 18-21. We next tested whether the EGFR was functional in both cell lines. Thus, SCLC cells were serum starved for $24 \mathrm{~h}$, followed by specific EGFR stimulation using $100 \mathrm{ng} \mathrm{ml}^{-1}$ EGF in the presence or absence of erlotinib (Figure 3B). Stimulation of SCLC cells caused a significant induction of p-ERK in both cell lines. Erlotinib blocked EGF-derived p-ERK induction in the GLC-4 cell line and reduced 
Table 2 Association between EGFR and mTOR pathways and clinical-pathological parameters $(n=107)$

\begin{tabular}{|c|c|c|c|c|c|c|c|c|c|c|}
\hline & EGFR & P-ERK & p-AKT & p-mTOR & p-p70s6K & ChemoTx & pT-stage & pN-stage & DFS & os \\
\hline p-ERK & $P=0.02$ & & $P=0.0001$ & NS & NS & NS & NS & NS & NS & NS \\
\hline $\mathrm{p}-\mathrm{mTOR}$ & $P=0.0001$ & NS & NS & & $P=0.001$ & NS & $P=0.048$ & NS & NS & NS \\
\hline p-p70s6K & NS & NS & NS & $P=0.001$ & & NS & $P=0.02$ & $P=0.001$ & NS & NS \\
\hline
\end{tabular}

Abbreviations: DFS = disease-free survival; EGFR = epidermal growth factor receptor; $\mathrm{mTOR}=$ mammalian target of rapamycin; NS = not significant; OS = overall survival; $\mathrm{p}-\mathrm{AKT}=$ phosphorylated AKT; p-ERK = phosphorylated extracellular signal-regulated kinase.
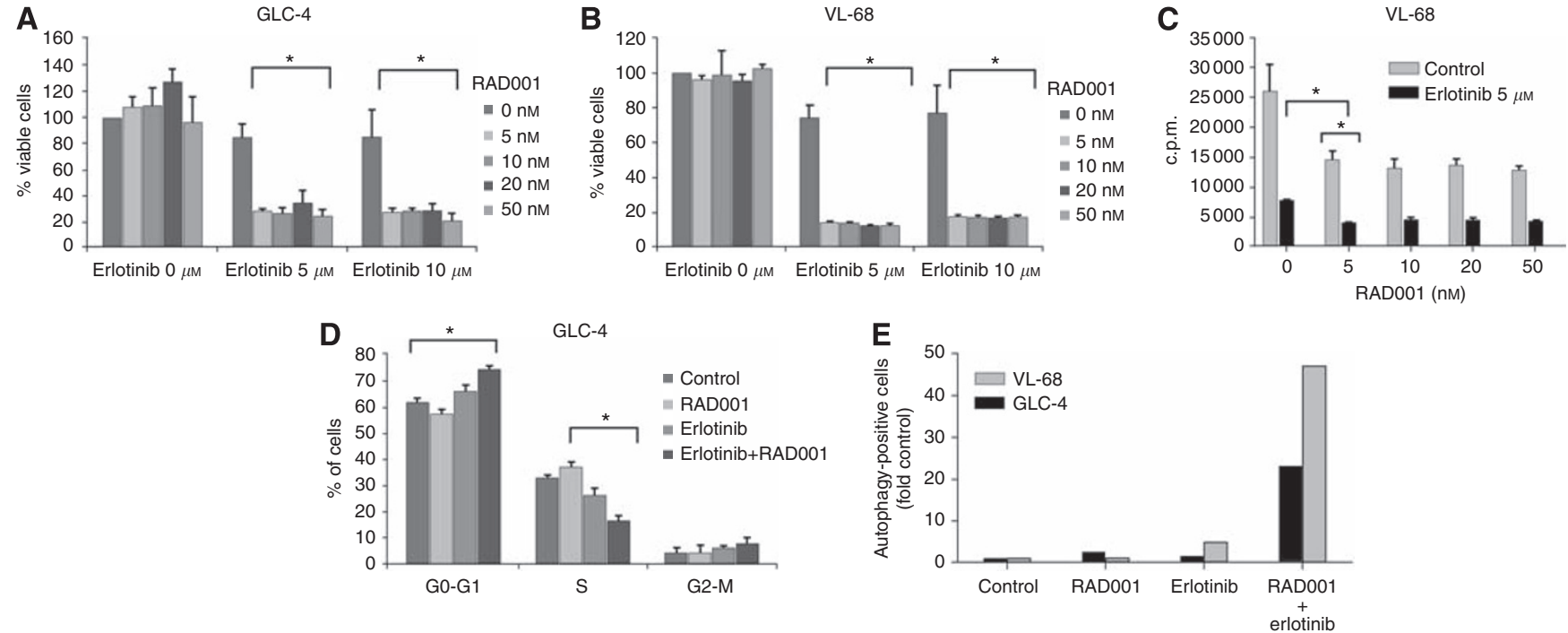

Figure 2 Effects on cell growth after treatment of SCLC cells with erlotinib, RAD00I and a combination of both. GLC-4 (A) and VL-68 (B) cells were treated with increasing doses of RAD00 I, erlotinib or a combination of both for $72 \mathrm{~h}$ and analysed for cell viability using the MTT assay. Data are given as mean percentage of viable cells \pm s.d. *Statistical significance $(P<0.05)$. $(\mathbf{C})$ VL-68 cells were treated with erlotinib $5 \mu \mathrm{M}$ or increasing doses of RAD00 I as indicated or a combination of both for $24 \mathrm{~h}$, and thereafter were analysed using the ${ }^{3} \mathrm{H}$-thymidine assay. Data are given as mean counts per min \pm s.d. *Statistical significance $(P<0.05)$. (D) GLC-4 cells were treated with $5 \mu$ m erlotinib, $10 \mathrm{nM}$ RAD00 I or a combination of both for $24 \mathrm{~h}$ and analysed by FACS after propidium iodide staining. Data are given as mean percentage of cells \pm s.d. *Statistical significance $(P<0.05)$. (E) VL-68 and GLC-4 cells were treated with $5 \mu \mathrm{M}$ erlotinib and $100 \mathrm{nM}$ RAD00 I or a combination of both for $48 \mathrm{~h}$ and analysed for acidic vesicular organelles. Data are given as $\mathrm{x}$-fold autophagypositive cells - one of three representative experiments is shown.

p-ERK induction to baseline levels in the VL-68 cell line (Figure 3B). The same was true for p-AKT in the GLC-4 cell line, whereas p-AKT was not inducible in the VL-68 cell line, a cell line lacking basal p-AKT expression. These data confirmed that the EGFR was functional in both cell lines and activated downstream targets upon activation with its ligand EGF.

Finally, we evaluated the effects of both drugs alone and upon combination on both cell lines: erlotinib monotherapy of GLC-4 cells with $5 \mu \mathrm{m}$ resulted in a clear downregulation of p-AKT, and significantly activated the mTOR pathway in terms of p-mTOR upregulation (Figure 3C), whereas erlotinib monotherapy of the p-AKT-negative VL-68 cell line with $5 \mu \mathrm{m}$ caused a significant downregulation of p-ERK levels, and - similarly to the GCL-4 cell line - significantly activated the mTOR pathway in terms of p-mTOR upregulation (Figure 3C). RAD001 treatment of GLC-4 and VL-68 cells with $5 \mathrm{~nm}$ resulted in the downregulation of p-mTOR and p-p70s6K. In addition, RAD001 influenced the EGFR pathway: there was a slight downregulation of p-ERK and p-AKT in the VL-68 and GLC- 4 cell line, respectively. The combination of $5 \mu \mathrm{m}$ erlotinib and $5 \mathrm{~nm}$ RAD001 in GCl-4 cells caused a synergistic downregulation of p-AKT compared with erlotinib and RAD001 monotherapy. In the VL- 68 cell line, the combination therapy synergised in terms of p-ERK downregulation compared with erlotinib monotherapy. In both cell lines, the mTOR pathway activation caused by erlotinib monotherapy was inhibited upon combination with RAD001.

\section{DISCUSSION}

Preclinical studies suggested synergistic effects upon combined EGFR and mTOR pathway inhibition in non-SCLC and breast (Buck et al, 2006), squamous cell carcinoma (Jimeno et al, 2007), glioblastoma (Wang et al, 2006), colon (Bianco et al, 2008), pancreatic cancer (Azzariti et al, 2008) and biliary tract cancer (Herberger et al, 2009). This is the first study testing the combination of EGFR targeting therapy with mTOR inhibitors for SCLC treatment.

First, we assessed single EGFR and mTOR pathway expression in 107 SCLC tissues. Surprisingly, EGFR receptor was expressed in $37 \%$ (see Table 2), which is more frequently than reported previously (Kaseda et al, 1989). In contrast, we found lower p-AKT and p-ERK expression when compared with other investigators (Blackhall et al, 2003). Moreover, we showed that expression of EGFR significantly correlated with its downstream target p-ERK. These results confirm in vivo the signalling information reported 
A VL-68 GLC-4

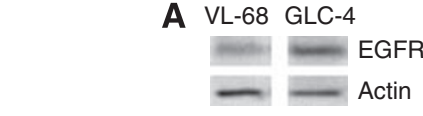

B

Erlotinib
EGF

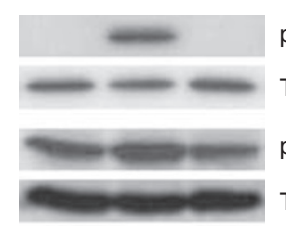

p-ERK

Total ERK

GLC-4

p-Akt

Total Akt

GLC-4

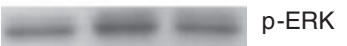

$=-m$ Total ERK

VL-68

p-Akt

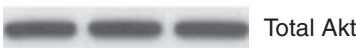

VL-68

VL-68

GLC-4

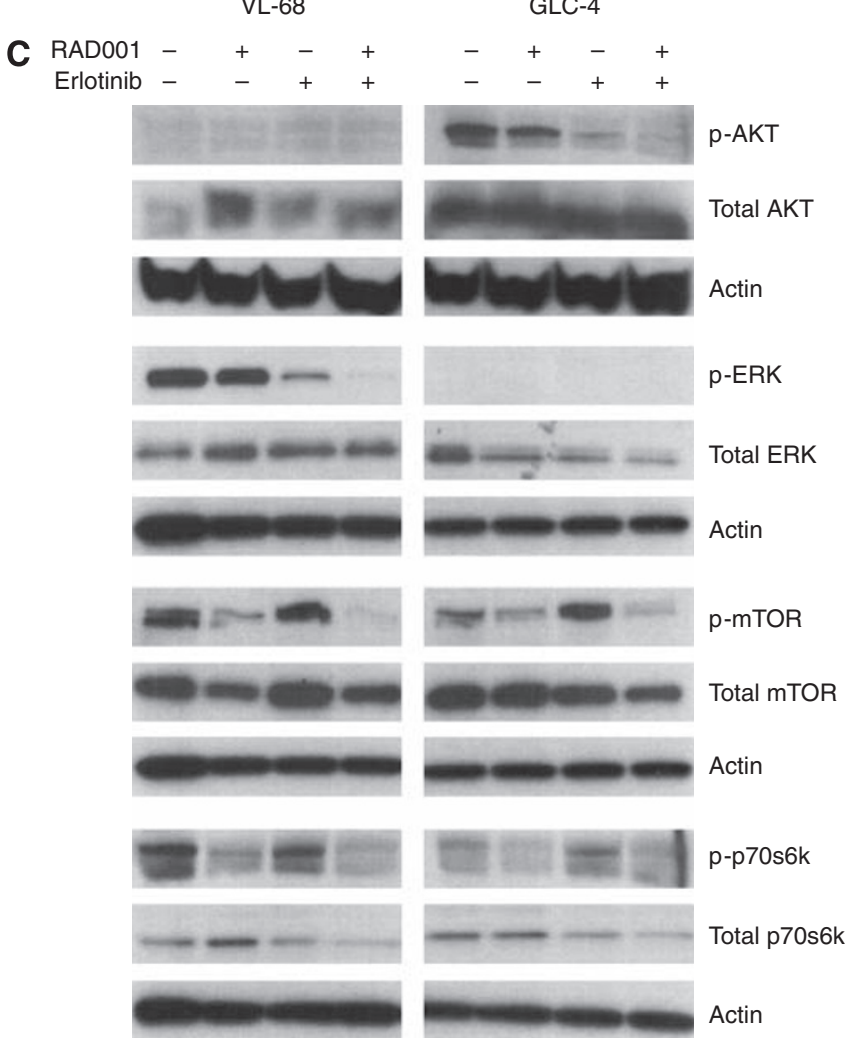

Figure 3 Effects on EGFR and mTOR pathways after treatment of SCLC cells with erlotinib, RADOOI and a combination of both. (A) GLC-4 and VL-68 cells do express EGFR. (B) GCL-4 and VL-68 cells were treated with $5 \mu \mathrm{M}$ erlotinib \pm EGF $\left(100 \mathrm{ng} \mathrm{m}^{-1}\right)$ for $10 \mathrm{~min}$ and blotted for $\mathrm{p}$-ERK, p-AKT and respective total proteins. (C) VL-68 and GCL-4 cells were treated with $5 \mu \mathrm{M}$ erlotinib, $5 \mathrm{nM}$ RADOOI or a combination of both for $24 \mathrm{~h}$, and then immunoblotted for total and phospho-protein expression of AKT, ERK, mTOR and p70s6K.

in various in vitro studies. Interestingly, patients receiving neoadjuvant chemotherapy with cisplatin and etoposid showed significantly lower EGFR expression than patients receiving no chemotherapy. Whether this reflects a true loss of EGFR receptor or a selection of EGFR-negative tumour cells remains to be investigated. However, reduced EGFR expression after chemotherapy could be, at least in part, responsible for the recent failure of a phase II clinical trial (Moore et al, 2006), testing gefitinib in chemotherapy pretreated SCLC patients.
The mTOR pathway was active in a significant proportion of patients in terms of p-mTOR (55\%) and p-p70s6K (84\%) expression (see Table 2). Similar to the association of EGFR and p-ERK, p-mTOR also showed its well-demonstrated association with p-p70s6K in vivo. Interestingly, mTOR pathway activation was stronger in earlier stages of disease. This finding could be important for future trial designs testing mTOR inhibitors in SCLC: a recently reported phase II clinical trial with the mTOR inhibitor everolimus (Owonikoko et al, 2008) in SCLC patients - including predominantly patients at an advanced stage of disease - failed to show significant clinical activity. In summary, EGFR and mTOR pathways were active in a significant proportion of patients with SCLC. Furthermore, $28 \%$ of SCLC patients showed coexpression of both pathways and may therefore represent the potential target population for combined anti-EGFR and mTOR targeting therapy.

Thus, we evaluated the efficacy of single- and dual-pathway inhibition in SCLC cell lines and investigated the mechanism of action of this combination at the molecular level. We found a synergistic antitumour effect upon combination of both drugs. The underlying mechanisms of the observed effect are complex and involve: (1) significant reduction of DNA synthesis (see Figure 2C), (2) a G0/G1 arrest with consecutive reduction of $S$ phase (see Figure 2D), and (3) induction of autophagy (see Figure 2E), a mechanism that has been recently reported for mTOR inhibitors (Kim et al, 2006; Iwamaru et al, 2007; Crazzolara et al, 2009). In combination, these effects significantly contributed to the observed antitumour effect, whereas apoptosis did not seem to play a major role (unremarkable DAPI staining, no evidence for a sub-G1 peak in FACS analysis).

It is noteworthy that there was only a mild effect of erlotinib at a physiological dose in both cell lines (see Figure 2A and B) despite strong downregulation of p-AKT in GLC-4 cells and p-ERK in VL-68 cells (see Figure 3C). This might be explained by the absence of an activating EGFR mutation, which is a striking predictor for sensitivity of tumour cells to EGFR targeting therapy (Lynch et al, 2004; Ono and Kuwano, 2006). Compatibly, the only reported case showing clinical response was achieved in a patient carrying one of these activating mutations (Okamoto et al, 2006). Furthermore, the induction of mTOR signalling by erlotinib observed in this study may have contributed to the blunting of antitumour activity.

Similar to erlotinib, the efficacy of RAD001 monotherapy was not dose dependent and was lacking in both cell lines, despite target regulation in terms of p-mTOR and p-p70s6K downregulation. In contrast to previous reports (Buck et al, 2006; O'Reilly et al, 2006; Sieghart et al, 2007), there was no increase in AKT phosphorylation, which could have caused RAD001 resistance, leaving the mechanism of resistance unclear. Taken together, single EGFR or mTOR pathway inhibition seems ineffective for SCLC treatment in vitro, which may explain recent failures of mTOR and EGFR monotherapy in clinical trials of SCLC (Moore et al, 2006; Owonikoko et al, 2008).

Crucially, dual inhibition of EGFR and mTOR pathways by erlotinib and RAD001 combination therapy showed a synergistic and highly significant antitumour effect that could be explained on the molecular level by synergistic regulation of both pathways (see Figure 3C).

In summary, we found that the EGFR and mTOR pathways are active and coexpressed in a significant proportion of SCLC patients. A combination of erlotinib and RAD001 showed a synergistic antitumour effect, which was reflected on the molecular level, whereas respective monotherapies failed to prove significant antitumour efficacy. Therefore, this study provides a preclinical rationale to test dual inhibition of EGFR and mTOR pathways in SCLC in a prospective clinical trial.

\section{ACKNOWLEDGEMENTS}

This study was supported by a research grant from Roche Austria. 


\section{REFERENCES}

Azzariti A, Porcelli L, Gatti G, Nicolin A, Paradiso A (2008) Synergic antiproliferative and antiangiogenic effects of EGFR and mTor inhibitors on pancreatic cancer cells. Biochem Pharmacol 75: 1035-1044

Belyanskaya LL, Hopkins-Donaldson S, Kurtz S, Simões-Wuest AP, Yousefi S, Simon HU, Stahel R, Zangemeister-Wittke U (2005) Cisplatin activates Akt in small cell lung cancer cells and attenuates apoptosis by survivin upregulation. Int J Cancer 117: 755-763

Berger W, Spiegl-Kreinecker S, Buchroithner J, Elbling L, Pirker C, Fischer J, Micksche M (2001) Overexpression of the human major vault protein in astrocytic brain tumour cells. Int J Cancer 94: 377-382

Bianco R, Garofalo S, Rosa R, Damiano V, Gelardi T, Daniele G, Marciano R, Ciardiello F, Tortora G (2008) Inhibition of mTOR pathway by everolimus cooperates with EGFR inhibitors in human tumours sensitive and resistant to anti-EGFR drugs. Br J Cancer 98: 923-930

Bjornsti MA, Houghton PJ (2004) The TOR pathway: a target for cancer therapy. Nat Rev Cancer 4: 335-348

Blackhall FH, Pintilie M, Michael M, Leighl N, Feld R, Tsao MS, Shepherd FA (2003) Expression and prognostic significance of kit, protein kinase $\mathrm{B}$, and mitogen-activated protein kinase in patients with small cell lung cancer. Clin Cancer Res 9: 2241-2247

Buck E, Eyzaguirre A, Brown E, Petti F, McCormack S, Haley JD, Iwata KK, Gibson NW, Griffin G (2006) Rapamycin synergizes with the epidermal growth factor receptor inhibitor erlotinib in non-smallcell lung, pancreatic, colon, and breast tumors. Mol Cancer Ther 5: $2676-2684$

Ciardiello F, Tortora G (2008) EGFR antagonists in cancer treatment. $N$ Engl J Med 358: $1160-1174$

Crazzolara R, Bradstock KF, Bendall LJ (2009) RAD001 (Everolimus) induces autophagy in acute lymphoblastic leukemia. Autophagy 5: $727-728$

Damstrup L, Rude Voldborg B, Spang-Thomsen M, Bruenner N, Skovgaard Poulsen H (1998) In vitro invasion of small-cell lung cancer cell lines correlates with expression of epidermal growth factor receptor. $\mathrm{Br} J$ Cancer 78: $631-640$

Dornetshuber R, Heffeter P, Kamyar MR, Peterbauer T, Berger W, Lemmens-Gruber R (2007) Enniatin exerts p53-dependent cytostatic and p53-independent cytotoxic activites against human cancer cells. Chem Res Toxicol 20: 465-473

Fischer B, Marinov M, Arcaro A (2007) Targeting receptor tyrosine kinase signalling in small cell lung cancer (SLCL): what have we learned so far? Cancer Treat Rev 33: $391-406$

Herberger B, Berger W, Puhalla H, Schmid K, Novak S, Brandstetter A, Pirker C, Gruenberger T, Filipits M (2009) Simultaneous blockade of the epidermal growth factor receptor/mammalian target of rapamycin pathway by epidermal growth factor receptor inhibitors and rapamycin results in reduced cell growth and survival in biliary tract cancer cells. Mol Cancer Ther 8: 1547-1556

Hidalgo M, Siu LL, Nemunaitis J, Rizzo J, Hammond LA, Takimoto C, Eckhardt SG, Tolcher A, Britten CD, Denis L, Ferrante K, vonHoff DD, Silberman S, Rowinsky EK (2001) Phase I and pharmacologic study of OSI-774, an epidermal growth factor receptor tyrosine kinase inhibitor, in patients with advanced solid malignancies. J Clin Oncol 19: $3267-3279$

Hudes G, Carducci M, Tomczak P, Dutcher J, Figlin R, Kapoor A, Staroslawska E, Sosman J, McDermott D, Bodrogi I, Kovacevic Z, Lesovoy V, Schmidt-Wolf IG, Barbarash O, Gokmen E, O'Toole T, Lustgarten S, Moore L, Motzer RJ; Global ARCC Trial (2007) Temsirolimus, interferon alfa, or both for advanced renal-cell carcinoma. $N$ Engl J Med 356: 2271-2281

Iwamaru A, Kondo Y, Iwado E, Aoki H, Fujiwara K, Yokoyama T, Mills GB, Kondo S (2007) Silencing mammalian target of rapamycin signaling by small interfering RNA enhances rapamycin-induced autophagy in malignant glioma cells. Oncogene 26: $1840-1851$

Jimeno A, Kulesza P, Wheelhouse J, Chan A, Zhang X, Kincaid E, Chen R, Clark DP, Forastiere A, Hidalgo M (2007) Dual EGFR and mTOR targeting in squamous cell carcinoma models, and development of early markers of efficacy. Br J Cancer 96: 952 - 959
Kaseda S, Ueda M, Ozawa S, Ishihara T, Abe O, Shimizu N (1989) Expression of epidermal growth factor receptors in four histologic cell types of lung cancer. J Surg Oncol 42: 16-20

Kim KW, Mutter RW, Cao C, Albert JM, Freeman M, Hallahan DE, Lu B (2006) Autophagy for cancer therapy through inhibition of proapoptotic proteins and mammalian target of rapamycin signaling. J Biol Chem 281: $36883-36890$

Lynch TJ, Bell DW, Sordella R, Gurubhagavatula S, Okimoto RA, Brannigan BW, Harris PL, Haserlat SM, Supko JG, Haluska FG, Louis DN, Christiani DC, Settleman J, Haber DA (2004) Activating mutations in the epidermal growth factor receptor underlying responsiveness of non-small-cell lung cancer to gefitinib. $N$ Engl J Med 350: $2129-2139$

Moore AM, Einhorn LH, Estes D, Govindan R, Axelson J, Vinson J, Breen TE, Yu M, Hanna NH (2006) Gefitinib in patients with chemo-sensitive and chemo-refractory relapsed small cell cancers: a Hoosier Oncology Group phase II trial. Lung Cancer 52: 93-97

Motzer RJ, Escudier B, Oudard S, Hutson TE, Porta C, Bracarda S, Gruenwald V, Thompson JA, Figlin RA, Hollaender N, Urbanowitz G, Berg WJ, Kay A, Lebwohl D, Ravaud A; RECORD-1 Study Group. (2008) Efficacy of everolimus in advanced renal cell carcinoma: a double-blind, randomised, placebo-controlled phase III trial. Lancet 372: 449-456

Nakamura Y, Oka M, Soda H, Shiozawa K, Yoshikawa M, Itoh A, Ikegami Y, Tsurutani J, Nakatomi K, Kitazaki T, Doi S, Yoshida H, Kohno S (2005) Gefitinib ('Iressa', ZD1839), an epidermal growth factor receptor tyrosine kinase inhibitor, reverses breast cancer resistance protein/ABCG2mediated drug resistance. Cancer Res 65: $1541-1546$

Okamoto I, Araki J, Suto R, Shimada M, Nakagawa K, Fukuoka M (2006) EGFR mutation in gefitinib-responsive small-cell lung cancer. Ann Oncol 17: $1028-1029$

Ono M, Kuwano M (2006) Molecular mechanisms of epidermal growth factor receptor (EGFR) activation and response to gefitinib and other EGFR-targeting drugs. Clin Cancer Res 12: $7242-7251$

O'Reilly KE, Rojo F, She QB, Solit D, Mills GB, Smith D, Lane H, Hofmann F, Hicklin DJ, Ludwig DL, Baselga J, Rosen N (2006) mTOR inhibition induces upstream receptor kinase signaling and activates Akt. Cancer Res 66: 1500-1508

Owonikoko TK, Stoller RG, Petro D, Flaugh R, Hershberger PA, Belani CP, Argiris AE (2008) Phase II study of RAD001 (Everolimus) in previously treated small cell lung cancer. J Clin Oncol Suppl 26: 19017

Pandya KJ, Levy DE, Hidalgo M, Cohen RB, Lee MW, Schiller JH, Johnson DH (2005) A randomized, phase II ECOG trial of two dose levels of temsirolimus (CCI-779) in patients with extensive stage small cell lung cancer in remission after induction chemotherapy. J Clin Oncol Suppl 23: 7005

Puglisi M, Dolly S, Faria A, Myerson JS, Popat S, O’Brien HE (2010) Treatment options for small cell lung cancer - do we have more choice? British J Cancer 102: 629-638

Sieghart W, Fuereder T, Schmid K, Cejka D, Werzowa J, Wrba F, Wang X, Gruber D, Rasoul-Rockenschaub S, Peck-Radosavljevic M, Wacheck V (2007) Mammalian target of rapamycin pathway activity in hepatocellular carcinomas of patients undergoing liver transplantation. Transplantation 83: 425-432

Tanno S, Ohsaki Y, Nakanishi K, Toyoshima E, Kikuchi K (2004) Small cell lung cancer cells express EGFR and tyrosine phosphorylation of EGFR is inhibited by gefitinib ('Iressa', ZD1839). Oncol Rep 12: 1053-1057

Wang MY, Lu KV, Zhu S, Dia EQ, Vivanco I, Shackleford GM, Cavenee WK, Mellinghoff IK, Cloughesy TF, Sawyers CL, Mischel PS (2006) Mammalian target of rapamycin inhibition promotes response to epidermal growth factor receptor kinase inhibition in PTEN-deficient and PTEN-intact glioblastoma cells. Cancer Res 66: 7864-7869

Wu C, Wangpaichitr M, Feun L, Kuo MT, Robles C, Lampidis T, Savaraj N (2005) Overcoming cisplatin resistance by mTOR inhibitor in lung cancer. Mol Cancer 4: 25

Zijlstra JG, de Vries EG, Mulder NH (1987) Multifactorial drug resistance in an adriamycin-resistant human small cell lung carcinoma cell line. Cancer Res 47: 1780-1784 